\title{
"Working from home is one major disaster": An analysis of student feedback at a South African university during the Covid-19 lockdown
}

\author{
Ilse Fouche ${ }^{1}$ (D) $\cdot$ Grant Andrews $^{1}$ (D)
}

Received: 3 February 2021 / Accepted: 23 June 2021 / Published online: 7 July 2021

(c) The Author(s), under exclusive licence to Springer Science+Business Media, LLC, part of Springer Nature 2021

\begin{abstract}
The Covid-19 global pandemic has resulted in many countries moving teaching and learning online. South Africa is a country with major inequalities in terms of access to electricity, internet and information technologies, which have created considerable problems for online learning at institutions of higher learning in the country. In this paper, we analyse student feedback from two large undergraduate English courses at a school of Education of a major South African university. We specifically focus on two qualitative questions which asked students about the challenges they faced and the skills they developed in online learning. Results are considered through the lens of critical digital pedagogies and decolonisation. Our findings indicate that a lack of access and resources, disruptive home environments and unfamiliarity with online learning methods were significant obstacles for students. In addition, many students indicated developing computer skills and learning how to use online resources during the courses. The study suggests that online teaching and learning in South Africa and similar contexts exacerbates inequalities, and must be accompanied by rigorous support structures for students who are vulnerable in these contexts.
\end{abstract}

Keywords Covid-19 · Critical digital pedagogy $\cdot$ Decolonisation · Online learning · Challenges

Ilse Fouche

ilse.fouche@wits.ac.za

Grant Andrews

grant.andrews@wits.ac.za

1 Division of Languages, Literacies and Literatures, University of the Witwatersrand, Johannesburg, South Africa 


\section{Introduction}

English courses traditionally rely on interactive classrooms where lecturers facilitate critical discussions between students. According to Cook et al. (2018), strong teacher-student relationships have long been considered a foundational aspect of a positive educational experience. These relationships are usually built during one-onone teaching. The two courses discussed in this study have always been characterised by the lecturers as facilitators of knowledge, actively guiding students towards discovering new knowledge in a face-to-face context. The Covid-19 pandemic, which forced all teaching to move online in South African higher education institutions, has created unprecedented challenges for lecturers to continue building the strong teacher-student relationships described by Cook et al. (2018). One problem has been that we as lecturers have little idea of the real-world challenges that our students experience when being forced to study online from their home environments. Additionally, due to the emergency nature of the move to online teaching, lecturers did not receive adequate training or clear understandings of how their online courses could be responsive to the needs of students in the South African context, and many lecturers simply reproduced the type of online teaching that they had already done in limited ways in the past. The aim of the study is therefore to determine what students' experiences, challenges and successes were when having to engage with our two courses online that ran in 2020.

We use student feedback from two undergraduate English courses as the data for this study. We specifically focus on two questions in the feedback that asked students about the challenges that they faced and the skills that they developed in online learning. We analyse these data in this study through content analysis, using theories of critical digital literacy and decolonial pedagogy to frame our analysis.

\section{Literature review}

Online teaching has several advantages. Many regularly cited advantages include its affordability, its flexibility with regard to accommodating a wider range of students than is possible with traditional full-time contact teaching, allowing anyone with an internet connection access to world-class education (simultaneously eliminating the need for additional costs such as travel and accommodation), increasing opportunities for global connections, allowing both synchronous and asynchronous learning, being student-centred, possibly enhanced interaction among students, allowing for more engaging lectures (due to attractive digital technologies) than traditional lecture halls, being provided with prompt feedback through tools such as online quizzes, and being linked to increased enrolment (Anthony et al., 2019; Castro \& Tumibay, 2021; Christie, 2004; Nguyen, 2015; Van Gelderen \& Guthadjaka, 2017). For cultural groups which have historically primarily valued aural/oral/visual modes of communicating, the fact that resources need not be limited to print literacy can lead to inclusivity (Van Gelderen \& Guthadjaka, 2017). 
There are however several potential pitfalls to online teaching, specifically in the Global South, but also with regard to marginalised and vulnerable students. The mere act of structuring an online learning module, an act that can so easily be assumed to be neutral, might make use of Western assumptions about how the world (and information) should be structured and transmitted (Van Gelderen \& Guthadjaka, 2017) and might also make assumptions of which epistemological frameworks students bring to institutions of higher learning. Lecturers might be less likely to pick up on such inconsistencies in a context where they do not know their students, and cannot observe misunderstandings as might have been possible in a face-to-face context. Smith (2016) adds a related problem, which he labels "translation"-_the transfer of meaning from human to a digital context and back to the human context". Thus, instead of a lecturer directly communicating with students in a classroom (a process already requiring a layer of translation and potentially fraught with misunderstanding), the digital context now acts as a mediator. The lecturer firstly has to translate intent to the digital platform, requiring a first layer of translation, after which the student needs to interact with this digital information and interpret it, requiring a second layer of translation. "This process of translation transfers meaning from a context fraught with emotive, contingent, and ambivalent relationships with human experience to a context in which these experiences become little more than binary digits stored in memory and back into a form meant to represent the initial subjectivity-laden elucidation of experience" (Smith, 2016). Smith (2016) adds that online learning might produce, or reproduce, a technocratic pedagogical approach, where educators unilaterally dictate learning environments, and in the process it could alienate groups of students.

The perceived advantages and disadvantages of online teaching are strongly connected to two general perceptions of technology. One sees it as neutral and equalising, while the other sees it as culturally situated and potentially problematic at various levels (Hinrichsen \& Coombs, 2013). The view adhered to will have significant implications "for policy, practice and curriculum" (Hinrichsen \& Coombs, 2013). These implications for online learning in specific can already be seen in debates around the issue between university management and academics. South African university decision makers would seem to generally gravitate towards seeing technology as neutral, an equaliser that empowers all students. There seems to be a particular drive towards institutionalising online learning which, the South African minister of Higher Education, Science and Innovation, Blade Nzimande, argues "must become a standard part for the future higher education system (Businesstech, 2020). As justification, he cites affordances such as it encouraging a "multimodal, blended approach to teaching and learning", giving students opportunities "to learn in different ways, more flexibly and at their own pace", and allowing for "multiple assessment methods" (Businesstech, 2020). Almost as a side note, Nzimande acknowledges that "a significant number of students, especially those at historicallyblack universities and campuses, and those living in working class and poor communities, have struggled to access digital platforms because of lack of devices, connectivity and other family household circumstances".

A group of over 300 academics have since co-signed a statement which challenges the narrative that online learning has been a success during the last three 
quarters of 2020, during which lockdown measures due to the Covid-19 pandemic have forced students into online learning from home (Pikoli, 2020). These academics question "the quality and substance of the education" that took place during this time, as well as the validity of marks obtained during this period. They further state that "online learning radically diminished the experimentation with ideas, the critical peer-to-peer learning environments [...and] the possibility of us learning from our students' lives and questions [...]. Moving online narrows and limits the scope of education - and its worth". The statement further points out that providing students with data and laptops does not sufficiently account for all of the challenges students face when having to study online from home. They warn that this strong drive towards online learning might be less due to the "success" that 2020 has been, and more due to the savings in investments such as classrooms and campus infrastructure that universities might achieve through moving curricula online.

This article examines the challenges and skills development of South African students in one of the country's leading universities with regard to the sudden move to online learning. By highlighting students' own perspectives and their responses to our two courses, we demonstrate how online learning is not meeting the needs of many South African students, or addressing many of the outcomes that they could expect from an in-person university education. We further show how university education before the sudden move to online learning failed to empower them with the necessary skills to seamlessly navigate this new mode of learning, but also highlight how students were able to acquire some of these skills on their own, under great pressure. Through using a decolonial theoretical perspective, the student feedback highlights how technologies do not act neutrally in the context of South African online learning, but might reproduce colonial discourses of knowledge and exacerbate structural inequalities that are still often tied to race in South Africa, particularly in English courses. In addition, we argue that institutions need to move towards a greater awareness and implementation of critical digital pedagogies, linked to an active awareness of decoloniality, to more effectively address the needs of these students.

\section{Theoretical framework}

In choosing a theoretical framework, we realised that we had to consider ways of teaching that are cognizant of, and responsive to the South African context, where online teaching is still a very novel approach that not many of our students use or are familiar with. Keeping this in mind, this study draws on two fields of theory in interpreting student feedback. These two fields are decolonial education and critical digital pedagogies.

\subsection{Decolonial education}

Decolonial education operates from an understanding that knowledge systems that are foundational to educational institutions, like schools and universities, are largely 
dependent on philosophical perspectives and epistemologies from the Global North which were disseminated through colonial and neocolonial enterprise. These perspectives and epistemologies are shrouded in discourses of "rationality", "neutrality" and "universalism" of knowledge production, research methods and ways of knowing that in fact are value-laden and do not account for indigenous knowledge systems that exist in countries in the Global South (Grosfoguel, 2007). This colonial knowledge system has obscured the fact that knowledge is contextually situated and dependent on a "locus of enunciation, that is, the geo-political and body-political location of the subject that speaks". Grosfoguel (2007) explains that "[b]y delinking ethnic/racial/gender/sexual epistemic location from the subject that speaks, Western philosophy and sciences are able to produce a myth about a Truthful universal knowledge that covers up, that is, conceals who is speaking as well as the geo-political and body-political epistemic location in the structures of colonial power/knowledge from which the subject speaks".

Prominent decolonial theorist Walter D. Mignolo (2007) explains that various historical and political factors led to the colonial matrix of power, a system which is rooted in capitalism and modernism, and locates power in the West. Valenzuela (2019) defines this colonial matrix of power as "enduring legacies of colonialism in the political, economic, social, and perhaps most especially, the educational realm". Mignolo (2010) argues for a process of epistemic delinking where "decolonial options, grounded in geo- and bodypolitics of knowledge, engage in both decolonizing knowledge and decolonial knowledge-making". However, Mignolo (2007) emphasises that "the Western foundation of modernity and of knowledge is on the one hand unavoidable and on the other highly limited and dangerous". Thus, it would be impossible to completely discard Western assumptions of knowledge even in contexts in the Global South, but consciousness of the colonial matrix of power as informing knowledge systems can lead to "decolonial options" (Mignolo, 2009) to challenge the hegemony of Western knowledge systems and the idea that knowledges, or the tools that facilitate or produce those knowledges, are neutral.

Within higher education, decolonial thought has influenced a greater awareness of the "ongoing struggles to resist everyday coloniality in the organizational structure, teaching methods, curriculum content and assessment mechanisms of the university" (Zembylas, 2018). This "require[s] a more critical understanding of the underlying assumptions and values that inform research, curriculum and pedagogical practices in higher education" (Zembylas, 2018). In our analysis, we take this critical and decolonial stance on information and communications technology (ICTs), the learning management system (LMS) and the pedagogical approaches we used within our two courses.

In addition, decolonial educators have emphasised that marginalised voices are important components in decolonial practice. As Silva et al. (2018) explain of decolonial pedagogy, "Dominant voices, perspectives, and narratives that often shape mainstream curriculum and textbooks are decentered in order to amplify the voices, experiences, and histories of students often erased in the classroom". Thus, we sought to centre the voices of students in this study in order for their perspectives to shape our analysis and to inform our practice as we continue to deliver online classes. Quotes from students' feedback are provided throughout our analysis to 
demonstrate their experiences of our courses. We use students' own words as far as possible for them to authentically represent their experiences.

\subsection{Critical digital pedagogies}

The debate between Nzimande and various other higher education decision makers on the one hand, and the group of South African academics on the other hand, has its roots in the two conflicting concepts of technological and social determinism. "Technological determinism is generally an implicit position, typified by conceptions of technological neutrality (a tool paradigm, open to positive or negative uses), autonomous advancement (we must adapt 'because it is here'; the dangers of being 'left behind') or proselytising (universally positive impacts; polarising constructions such as 'dinosaurs' or 'luddites')" (Hinrichsen \& Coombs, 2013). The dominance of this view is often still visible at policy and institutional levels (Hinrichsen \& Coombs, 2013), as is evidenced by Minister Ndzimande's stance discussed above. Social determinism, on the other hand, holds that technology is never neutral, but is rather influenced by socio-cultural, economic as well as political factors. One concept in particular that is increasingly criticised is that of the "digital native" (Prensky, 2001), which refers to those born in the era of greater access to technology who are assumed to be innately proficient with various types of technology. Smith (2016) states that "[t]he current generation of students live and learn within a pedagogical milieu saturated by digital technologies". This, in itself, is based in a Western-centric and possibly middle/upper-class worldview. Furthermore, the assumption that the current generation of students is automatically fluent in the use of technology is problematic at various levels, including the range of students' digital abilities (Margaryan et al., 2011), the lack of transfer between informal settings to formal learning (Littlejohn et al., 2012), and disassociation between students' social and academic identities (Hinrichsen \& Coombs, 2013; Mendelson \& Papacharissi, 2010). Hinrichsen and Coombs (2013) argue that "it is clear (...) that broader literacy practices are not going to emerge spontaneously as a result of technology proliferation or early exposure and that education has an important role in inculcating, moderating and extending such practices".

The concepts of technological and social determinism, as well as the assumption of students being "digital natives", are important when considering critical digital pedagogies. In Freire's (2005) view, critical pedagogy takes into consideration that education is political, and that by its nature, it can disadvantage certain students. The purpose of literacy education, in his view, is to challenge and overturn both political and social inequalities. Critical digital pedagogy, then, acknowledges that any technological artefact or mode used for education purposes will have limitations, and that though digital tools will make some power structures visible, they are just as likely to obscure others (Waddell \& Clariza, 2018). For a student population to 
effectively engage in online learning, critical digital pedagogies that work towards empowering students, but also taking the restraints of their realities into consideration, are vital.

Smith (2016) suggests three considerations in an attempt towards decolonising digital artefacts. It is important to note that he discusses these in the context of teaching computer code specifically. However, these considerations can effectively be transposed to the general context of online learning and teaching. Firstly, he warns against obfuscation. In the field of computer programming, obfuscation refers to hiding "secrets inside a program while preserving its functionality" (Lynn et al., 2004). When that concept is extrapolated to online learning, one might argue that meaning (through content) could be obfuscated in the "programming" of one's course: its structure, the language used, and its general accessibility. This might be a purposeful act, or it might happen as a result of a lecturer who, for example, does not understand or take into consideration his/her student population's (or populations') experience and skill level in interacting with the prerequisite online artefacts, or hurdles they face in doing so due to their socio-economic circumstances. The level of accessibility and language of online artefacts have the potential of overcoming the traditional barriers found in most Western universities that often act as gatekeepers against non-traditional student populations, but without careful thought and conscious design, they might also entrench these barriers.

The second consideration is that of translation (Smith, 2016). The mode of online pedagogy poses the danger of removing lecturers from the lived experiences of their students. As discussed earlier, the translation of knowledge is already part of teaching (to use Smith's metaphor, one makes a copy of a copy). However, when that knowledge, from both the direction of the student and the lecturer, first needs to be encoded through the mediator that is the online artefact, a double translation is necessary. A danger exists that in a context where students (and their realities and experiences) are physically removed from the immediate environment in which the lecturer teaches, that this double translation might very well fail to take into account vulnerable students already struggling with a Western-dominated academic discourse, thus further entrenching neocolonial domination.

The third consideration mentioned by Smith is that of technocratic engendering. Smith (2016) argues that "the proliferation of mobile technologies has created a new type of privilege, one that benefits a select few who have access to the means of production." Smith (2016) warns against producing (and by implication using) tools that might be beyond various student populations' ability to use effectively with the levels of computer literacy with which they enter our classrooms. In his words, "I automatically limit who has access to the means of making representations; in using this medium, I limit the role of 'story disseminator' to myself and the other few who can 'speak code"'.

For this study, we were interested in the lived experiences of students in a developing nation with regard to online learning, in addition to being critical of our own practices in how we taught courses using digital technologies, while working 
towards a decolonised learning space. We were particularly interested in the extent to which the mode of online learning provided students with access into academic discourse and knowledge structures, or whether it entrenched those barriers that, purposefully or not, prevent marginalised students from partaking in the academe.

\section{Methodology}

The two researchers involved in this project identified this research opportunity during the midst of the Covid-19 pandemic in 2020, while teaching their respective second term courses for English I (Media Stories) and English II (Grammar) in the BEd course at the *** (hidden for anonymity). Data were gathered in May 2020, two months into the South African lockdown, during which all contact classes at schools and universities were suspended, student residences were closed, and all students were expected to engage in online learning from their homes. The gathered data were part of yearly course evaluations for both courses; these course evaluations are a routine part of improving courses.

Ethical clearance for this project was obtained from the University of the Witwatersrand. Questionnaires, links to which were posted as announcements on the students' learning management system, were administered through Google Forms. Settings on the Google Forms platform were adapted to ensure that all feedback was anonymous. Furthermore, students were asked to indicate their consent to their responses being used for research purposes, and only those responses of students who consented were used in this study.

Open-ended qualitative questions were posed to students in addition to standard Likert-scale questions. This paper focuses on two of the open-ended questions, which aimed to determine students' challenges in the process of online learning, and also to ascertain which skills they were able to develop during this time. These questions read as follows:

- What have been your greatest challenges with regard to online learning?

- Which new technological skills have you acquired during the online learning process, or which skills have you improved?

Data from qualitative questions were analysed by means of content analysis. Babbie (2013) defines content analysis as being the study of human communications. In content analysis, writing is coded into emerging themes. Benaquisto (2008) describes the coding process as "steps the researcher takes to identify, arrange, and systematise the ideas, concepts and categories uncovered in the data". Codes and accompanying themes were identified through a thorough analysis of student feedback, so as to identify patterns and units of meaning from student feedback. The researchers validated the codes by moderating each other's coding. Where appropriate, codes were merged into meaningful themes. Themes are discussed based on the frequency at which they emerge from student feedback. Figure 1 illustrates the research process followed for this article. 


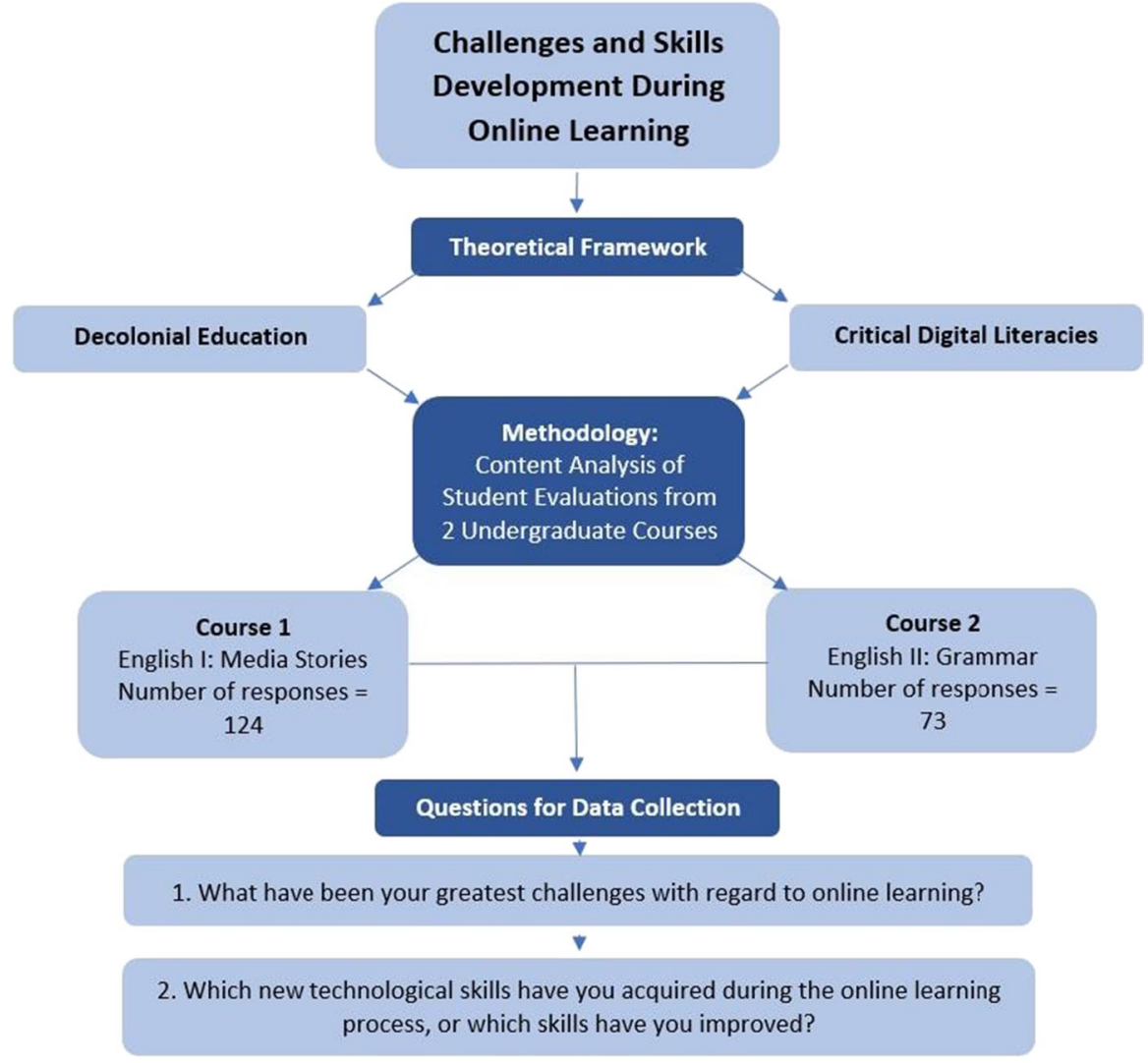

Fig. 1 Design and methodology of the study

\section{Findings and discussion}

The data from feedback on the two open-ended questions are presented and analysed in this section. In order to understand the online learning context of the students, we also asked them to indicate the types of devices that they had access to during online learning. Our university loaned 5000 laptops to students and staff who did not own devices, which many students indicated as "borrowed laptop" in their feedback, but some students also indicated borrowing laptops from neighbours or relatives in their written responses. It is important to note that the number of laptops provided by the university were not enough to provide one for each student who needed one. Students' access to devices are indicated in the table below. Percentage totals do not add up to $100 \%$, as many students had access to more than one device.

The responses in Table 1 (visually illustrated in Fig. 2) show that smartphones were the most accessible device. Additionally, over half of students who responded to the surveys in each course had their own laptops. A large percentage of students used borrowed laptops (almost one in five English I students 
Table 1 Which of the following devices have you had available to you while working on this course?

\begin{tabular}{lllll}
\hline & $\begin{array}{l}\text { English I } \\
\text { Number of } \\
\text { responses } \\
{[n=124]}\end{array}$ & $\begin{array}{l}\text { English I } \\
\text { Percentage }\end{array}$ & $\begin{array}{l}\text { English II } \\
\text { Number of } \\
\text { responses } \\
{[n=73]}\end{array}$ & $\begin{array}{l}\text { English II } \\
\text { Percentage }\end{array}$ \\
\hline $\begin{array}{l}\text { Smartphone (Cellphone with } \\
\text { internet access) }\end{array}$ & 75 & $60.5 \%$ & 52 & $71.2 \%$ \\
$\begin{array}{l}\text { Own laptop } \\
\text { Borrowed laptop }\end{array}$ & 72 & $58.1 \%$ & 41 & $56.2 \%$ \\
Tablet & 24 & $19.4 \%$ & 18 & $24.7 \%$ \\
Own desktop computer & 5 & $4.0 \%$ & 2 & $2.7 \%$ \\
Borrowed desktop computer & 3 & $3.2 \%$ & 1 & $1.4 \%$ \\
\hline
\end{tabular}

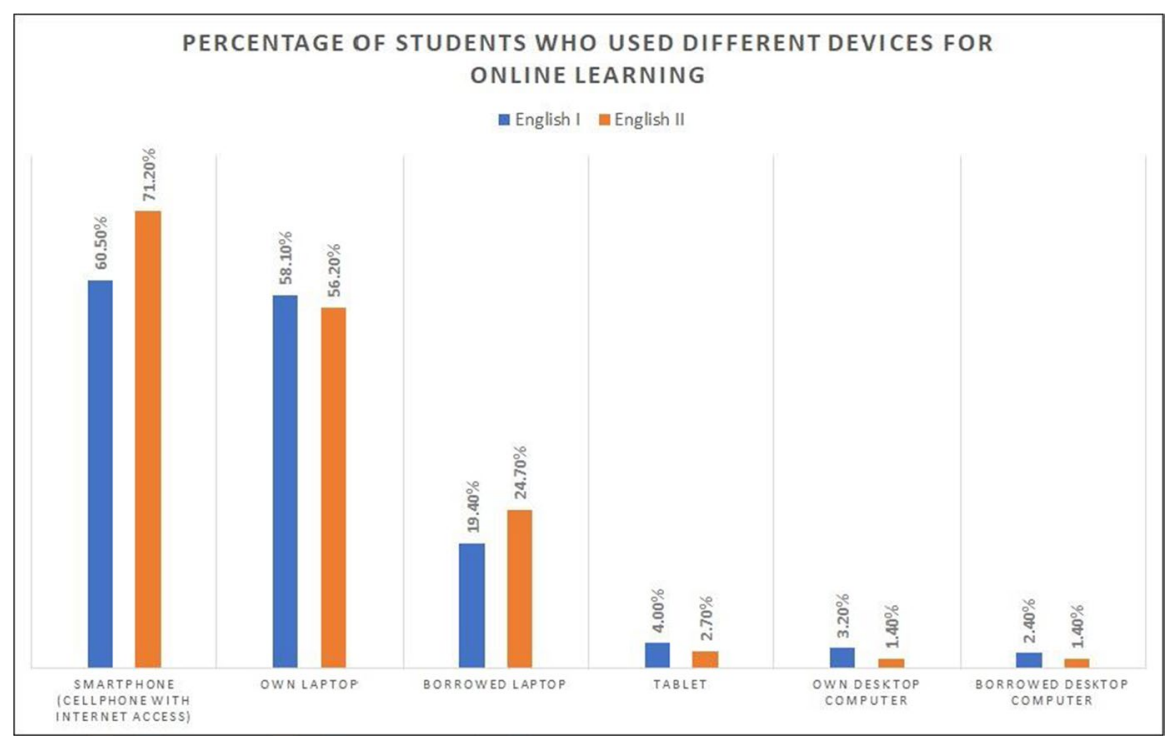

Fig. 2 Percentage of students who indicated using specific types of devices for online learning

and one in four English II students). Significantly, 24 English I (19.4\%) and 12 English II (16.4\%) students indicated that they only had access to a smartphone for their online learning, meaning that they could only access course materials through very small screens, which likely impacted ease of reading, typing and managing online resources. This was especially significant in the English I course where visual elements of media were part of the course, and only having access to cellphones might have placed these students at a disadvantage in analysing these visual texts. 


\subsection{Greatest challenges}

Firstly, students were asked the following:

What have been your greatest challenges with regard to online learning?

This question was answered by 116 students in the English I course and 61 students in the English II course. Table 2 (graphically represented in Fig. 3) indicates the number of student comments surrounding each of the themes discussed below.

Table 2 What have been your greatest challenges with regard to online learning?

\begin{tabular}{lllll}
\hline & $\begin{array}{l}\text { English I } \\
\text { Number of } \\
\text { responses } \\
{[n=116]}\end{array}$ & $\begin{array}{l}\text { English I } \\
\text { Percentage }\end{array}$ & $\begin{array}{l}\text { English II } \\
\text { Number of } \\
\text { responses } \\
{[n=61]}\end{array}$ & $\begin{array}{l}\text { English II } \\
\text { Percentage }\end{array}$ \\
\hline $\begin{array}{llll}\text { Structural challenges } \\
\quad\end{array}$ & 55 & $47.4 \%$ & 33 & $54.1 \%$ \\
$\quad$ Poor internet connection & 14 & $12.1 \%$ & 6 & $9.8 \%$ \\
$\quad$ Power cuts & 9 & $7.8 \%$ & 0 & $0 \%$ \\
$\quad$ Problems regarding physical devices & & & & \\
Workload and time management & 30 & $25.9 \%$ & 17 & $27.9 \%$ \\
$\quad$ Workload & 21 & $18.1 \%$ & 10 & $16.4 \%$ \\
$\quad$ Time management & 12 & $10.3 \%$ & 12 & $19.7 \%$ \\
$\quad$ Home life & 7 & $6 \%$ & 4 & $6.6 \%$ \\
$\quad$ New to online learning & & & & \\
\hline
\end{tabular}

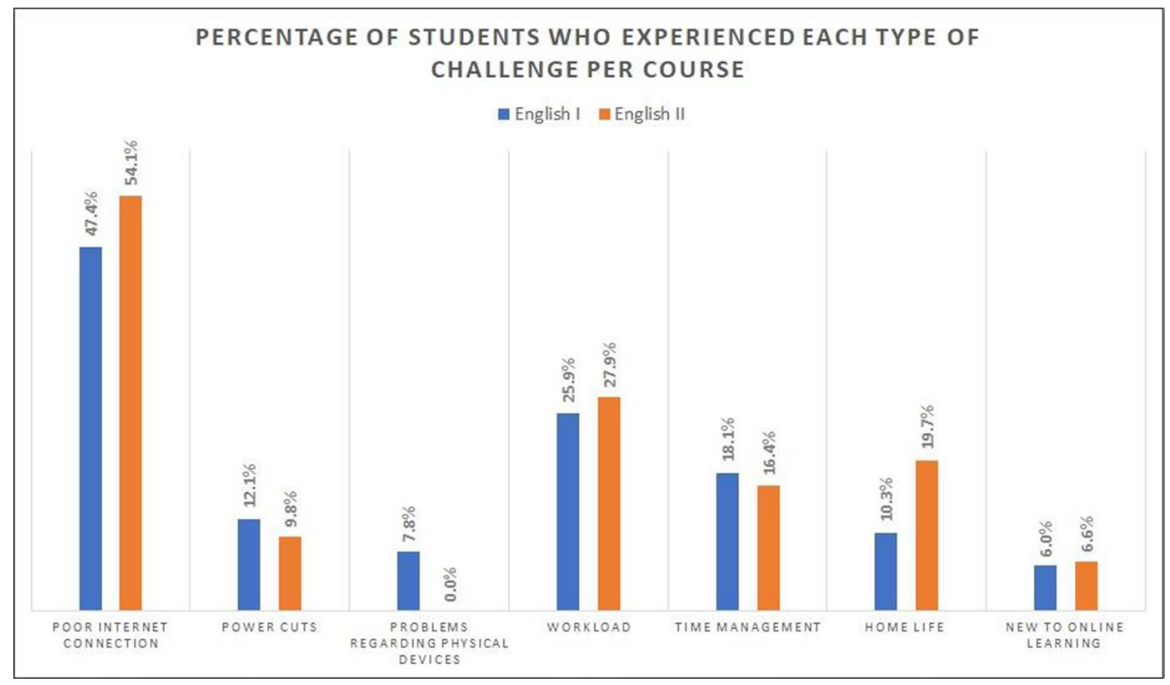

Fig. 3 Graphical representation of challenges in each course 


\subsubsection{Structural challenges}

By far the greatest theme that emerged from student responses was that of the structural realities of having to study from home in the South African context, with well over half of all responses focusing on structural challenges experienced. These structural challenges centred around three areas: firstly, poor internet connection in many areas; secondly, frequent planned (called loadshedding) and unplanned power cuts due to an inadequate and poorly maintained South African electricity power system; and thirdly, issues surrounding obtaining the necessary physical devices, such as computers and smartphones, for online learning.

A disconcerting percentage of students across both courses found poor internet connection to be the biggest challenge in their online learning journey. Students called network connectivity "the greatest challenge", "really bad" as well as " $a$ pain"; "[a]t times it disconnects and I cannot login and access daily tasks", and "I have network problems, when I try to hotspot my laptop to watch videos". Two comments particularly indicated the reality of many South African university students living in rural areas: "Internet connection is a problem sometimes I'm delayed and fall behind due to poor net work in my village" and "Network coverage [has] been my biggest challenge. I have to go to the kraal [a circular livestock enclosure found in settlements or villages] everytime I want to study or write a test. Its so hard for $m e$ ". Despite some data being provided to students by the university, this was also a significant hurdle. Half of the provided data could only be used between midnight and 5am (called night data), and as these comments indicate, this created significant difficulties. One student indicated that it was challenging "having to study at midnight in the cold to use the data given to everyone by the institution", while others added comments such as that "My data would get finished and it wasn't cheap to buy some". One student indicated the reality of having to share this limited and precious data in a home environment: "Managing the day data, while the night data was not in use, as a mother my children are also doing online [learning]". South Africa is a vast country, and stable internet connection is often only found in cities and large towns, while many of our students live in rural areas and small towns. Although students were provided with $10 \mathrm{~GB}$ data per month to engage in university work, this gesture was simply not sufficient for the realities of a large proportion of our students.

Another structural challenge that South African students face is that of regular power cuts. "There is always load shedding [planned power cuts] in my location and material is digital, when my devices become flat there is nothing $i$ can do". Another student agrees, saying a big problem was "Lack of electricity, 2 days without electricity can distract my weekly plan completely. I have to work beyond schedule in order to catch up with my workload'. Most South African universities have acquired back-up generators at their campuses to manage the power cuts that have become part of South African life, but that is not a luxury most of our students have at their homes.

A final structural challenge students mentioned was problems around using or acquiring physical devices from which online learning can occur. It is interesting that only first-year students in the English I course specifically commented on this 
being a particular challenge, although the results from the survey question discussed at the beginning of this section clearly indicate that many students across both courses do not own a laptop, desktop computer, or tablet. Some students indicated that using smartphones for online learning was challenging, like one student who was "struggling to cope since I'm not using a laptop", and another student who indicated "the inability of my phone downloading documents". Other students had to share devices, such as a student who indicated that "I share a laptop with my parents so I couldn't use it when I wanted to" or another student who had "to borrowe a laptop from someone who also uses it in daily basis". Others had old or poor quality devices, like a student who often encountered "laptop errors", or one who complained that his/her "devise was very slowly".

These three structural barriers to students fully and effectively participating speak to broader social realities in South Africa and cannot be remedied solely by the lecturer or the institution. Yet, their implications for large subsections of students are undeniable. These structural barriers in and of themselves create a nonneutral learning environment (cf. Hinrichsen \& Coombs, 2013) in which privileged students are much more likely to meet the demands of online education than the many vulnerable students at our universities; this relates to Smith's (2016) concept of technocratic engendering, which "has created a new type of privilege, one that benefits a select few who have access to the means of production". These challenges might well work towards alienating groups of students (cf. Smith, 2016), disempowering them before they have even started engaging with online content. Should online learning become a "standard part for the future higher education system", as Nzimande (Businesstech, 2020) advocates for, without providing students with necessary structural support, former colonial perimeters will not only be affirmed, but also strengthened. This structural support cannot be limited to data and devices, but must extend to creating spaces for all students where realities such as network connectivity and regular power failures are eliminated.

\subsubsection{Workload and time management}

Other challenges that strongly featured in student responses were those of workload and time management. Students described the workload as "overwhelming" and "insane", and themselves as being "unable to cope". One student spoke to "the overwhelming workload and increased submissions with looming deadlines yet not much guidance from some lecturers. Self-teaching is hard." Another student found it difficult "Keeping up with e-mails from each lecturer and keeping track of ever changing and newly added tests and assessments by different lecturers". This resulted in students who were "Sometimes ... left behind and end up not submitting some of the tasks".

Two things stand out here. Firstly, there is the contradiction that we found repeatedly in student comments that some felt they did not receive enough guidance and communication from lecturers, while others felt that there was too much communication. This was found in both courses (in fact, approximately $6 \%$ of responses focused on either a lack of, or an excess of, communication), and points to a general feeling of being overwhelmed. It is also worrying that so many students complained 
about too heavy a workload. Lecturers presenting the courses under discussion were explicitly asked to reduce the content as well as assessments in each course, as we anticipated that students would find online learning challenging. Content was often cut by as much as $20 \%$, with fewer assessments throughout. Work was also often simplified to allow students to cope in the extraordinary circumstances brought about by Covid-19. Yet, a significant number of students still did not feel up to the task. Secondly, it was interesting that some students considered online teaching as "self-teaching". From the perspective of the authors, we spent even more time than in previous years on teaching these courses. Much more effort was needed to create clear and concise narrated powerpoints, podcasts, videos, instructions and explanations. We made an effort to introduce ourselves and stay in regular contact with our students, encouraging them to attend virtual consultation hours and to contact us throughout via email or online forums. Yet, it would seem that in online teaching students struggle to build a relationship with, or attach a persona to, a lecturer, and in this process, much value in the teacher-student relationship is lost. Some students specified that they preferred "direct contact" and missed "face to face interaction with the lecturer", with one student stating that she experienced the lecturer positively, but mainly because "I already know her from the campus". Another reason why students struggled might have been that "There are many activities and one has to read in order to understand no one clarifies for you" [own emphasis]. The lack of face-to-face contact sessions and consultations would seem to have adversely impacted many students.

Time constraints and deadlines were another significant challenge, as one student explains: "We have received overwhelmingly large amounts of assignments, tests and quizzes with unmanageable, difficult and anxiety-inducing deadlines-contributing to mental health issues in an already burdening (global) life crisis. Deadlines should have been extended to make it manageable.". Again, deadlines were extended in almost all courses during this lockdown period, and much was done to accommodate students as much as possible if they could not meet deadlines. Yet, the anxiety caused directly by Covid-19, and indirectly by having to study from often challenging home environments without physical contact with lecturers and fellow students, seemed to create an environment in which students were unable to manage the same pressures as in normal learning/teaching environments. Interestingly, several students identified time management as a problem, often acknowledging that their own ability to self-regulate time caused their struggles with workload. One student notes that "My greatest challenge was time management, I was unavailable to balance my work but now I'm trying to manage my time unlike the first week of the online classes". Others admit to "procrastination", struggling with "Adhering to due dates" and "Managing how to divide my time".

The severe anxiety evidenced by students' comments on workload and time management speak to a dissonance between student and lecturer expectations. We have never experienced students struggling with workload requirements to nearly the same extent during traditional contact teaching, despite ensuring an already reduced student workload due to the move to online teaching. The data suggest that Smith's (2016) concept of double translation partially accounts for why students find the workload so overwhelming. The student who said that "no one explains for you" 
not only had to interpret information that had already been translated twice, but was also hesitant to ask the lecturer for further explanation (and thus further translation) as the student might have done during contact teaching. Obfuscation (Smith, 2016) might also be at play, in that lecturers might feel under pressure to create impressive online lessons that make use of a variety of online tools, without taking into account that students who are inexperienced in online teaching might take much longer in interacting with the content than peers who have had more exposure to online artefacts. Even the structure of LMSs might rely on epistemological frameworks that favour some students at the expense of others (cf. van Gelderen \& Guthadjaka, 2017).

\subsubsection{Students' home lives}

Another emerging theme related to difficulties in managing time is the challenges students experienced studying from home. Many of our students stayed at university residences before lockdown, which created some structure for academic engagement. However, many had to return to home environments that were "not conducive for learning". Many students are also first-generation students who come from households that do not understand how much time is required for tertiary studies. Students cited "too much noise" from children as well as noisy neighbourhoods, "not enough time to study", "chores", "distractions", and not having "enough space". Some notable comments include the challenges of "having to deal with the small space and kids all over the place and working at the same time", "having time to study as I live with 11 family members and I have tons of home chores", and "Having the house chores and many siblings to take care of, while trying to keep up with the work load". One student stated that "the environment I am living in is not good for me", while another more bluntly stated that "working from home is one major disaster". Small, crowded, uncomfortable living spaces is not only a reality for many South African students, but also for students from developing countries and poor environments across the world. Yet, these contexts are often disregarded in decisions regarding online teaching. Though some scholars argue that anyone with an internet connection can access world-class education (cf. Castro \& Tumibay, 2021; Nguyen, 2015), the reality for many students in the Global South, as for many vulnerable students worldwide, is far more nuanced. Implying that students facing the abovementioned challenges can take the same advantage of online education as a middleclass student in a more conducive environment (cf. Hinrichsen \& Coombs, 2013) for a discussion of the concept of technological determinism) is socioeconomically insular, and is insulting to the lived realities of multitudes of students. It speaks to a colonial mindset of homogeneity which should be challenged not only in the Global South, but in any institution that caters to students from diverse backgrounds.

In addition to the challenges listed above, our students were also almost all new to the mode of online learning, which created a lot of anxiety, especially when combined with the factors discussed above. Students stated that they were "Battling to adapt", having to study online "without having any prior experience", that they had a "lack of understanding how technology works" and having to "[read] on my own". One student indicated that they still needed to print out 
reading materials to annotate on hard copies, presumably because they struggled to annotate and interact with texts electronically. Already overburdened lecturers might assume that their (now largely faceless) students enter (or at least should enter) university studies with epistemological frameworks (cf. van Gelderen \& Guthadjaka, 2017) that enable them to adapt to the required mode of teaching. This might well lead to a technocratic pedagogical approach (cf. Smith, 2016), devoid of the richness that a diverse student body often brings to contact teaching (cf. Pikoli, 2020), potentially fraught with a myriad of instances where information and learning are unintentionally obfuscated (cf. Smith, 2016) from students who have never had to engage in online learning.

Several other challenges that were mentioned by students were the difficulty with adapting to academic reading, the way in which they were assessed, their general emotional state, the struggle to learn independently, not understanding content, and finding material online. Only four students across the two courses stated that they experienced no challenges at all, with only one saying that s/he preferred online learning to contact learning. The general sense we had when analysing students' comments was that the experience "is very overwhelming", "causing me to stress", "extremely hard" and students feeling that "pressure [was] put on me".

Despite all of these challenges, students seemed to have learned various skills in this time. This is discussed in the next section to demonstrate some of the affordances of online learning, but also to show the varying skill levels of students and the types of training and preparation that should be incorporated in ongoing online learning environments.

\subsection{Improvement of skills}

The second qualitative question we asked of students was the following:

Which new technological skills have you acquired during the online learning process, or which skills have you improved?

We aimed to gauge how students experienced the courses as contributing to their proficiency with ICTs, and to understand how our courses were challenging students to become more familiar with the tools that were required for online learning.

This question was answered by 108 students in the English I course, and 53 students in the English II course. Table 3 (graphically illustrated in Fig. 4) indicates the number of student comments for each of the themes discussed below.

Students indicated a range of skills that were developed while completing the two courses. Most of these skills were similar for the feedback in the English I and English II courses. The highest percentage of responses were recorded for the following skill categories: computer and mobile device skills, including typing skills; online learning skills; and time management skills. Significantly, 9.3\% of English I students and $13.2 \%$ of English II students indicated that they had no skill improvements. 
Table 3 Which new technological skills have you acquired during the online learning process, or which skills have you improved?

\begin{tabular}{lllll}
\hline & $\begin{array}{l}\text { English I } \\
\text { Number of } \\
\text { responses } \\
{[n=108]}\end{array}$ & $\begin{array}{l}\text { English I } \\
\text { Percentage }\end{array}$ & $\begin{array}{l}\text { English II } \\
\text { Number of } \\
\text { responses } \\
{[n=53]}\end{array}$ & $\begin{array}{l}\text { English II } \\
\text { Percentage }\end{array}$ \\
\hline $\begin{array}{l}\text { Computer and mobile device } \\
\text { skills }\end{array}$ & 49 & $45.4 \%$ & 15 & $28.3 \%$ \\
$\begin{array}{l}\text { Typing } \\
\text { Online learning skills }\end{array}$ & 23 & $21.3 \%$ & 15 & $28.3 \%$ \\
Time management & 22 & $20.4 \%$ & 10 & $18.9 \%$ \\
Collaboration & 9 & $8.3 \%$ & 6 & $11.3 \%$ \\
Independence & 4 & $3.7 \%$ & 3 & $5.7 \%$ \\
No skills improved & 10 & $3.7 \%$ & 1 & $1.9 \%$ \\
\hline
\end{tabular}

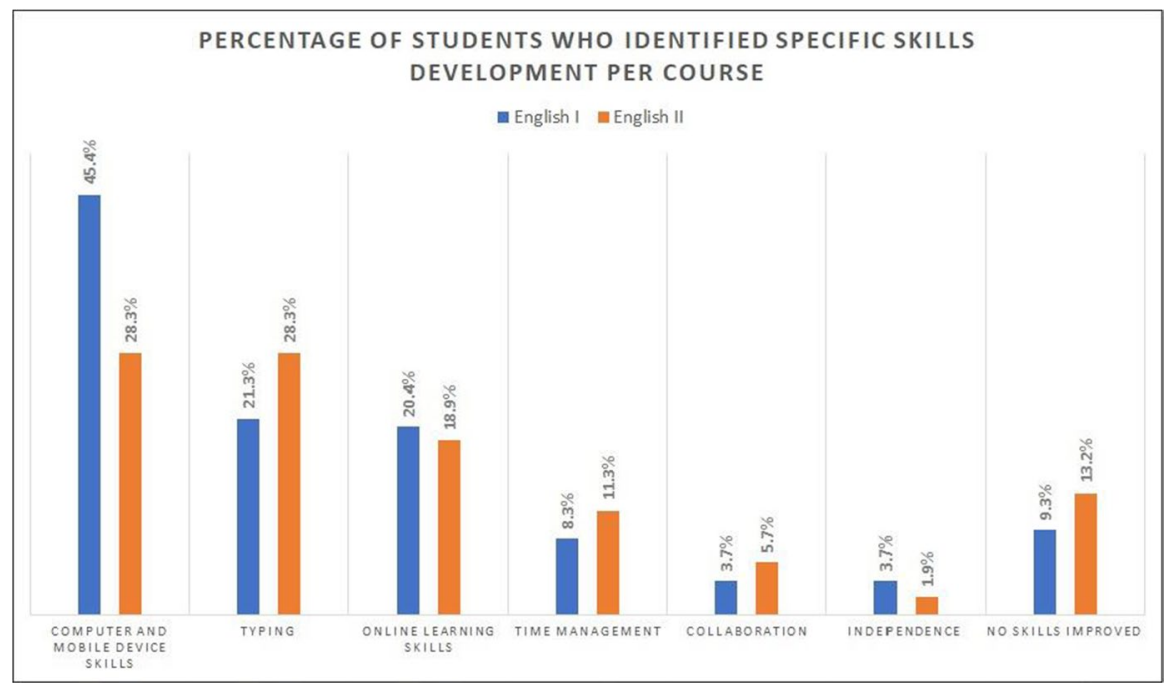

Fig. 4 Graphical representation of skills improvement in each course

\subsubsection{Computer and mobile device skills}

The largest proportion of students who responded to this question indicated that they developed skills with using computer hardware or software, or mobile devices. Many students indicated that they had developed a greater understanding of how to use Microsoft Word and PowerPoint, as well as video conferencing software like Microsoft Teams and Zoom. Comments included: "I have developed digital skills, and have also learnt a lot about software"; "Creating diagrams on a laptop"; "Downloading materials online and watching YouTube videos online.i learned how to use my phone's many features like editing and putting annotations to a written document". Notably, a much higher percentage of English I students expressed that 
they developed computer/ mobile device skills (45.4\%) compared to English II students $(28.3 \%)$, indicating that students at more advanced levels of study had already developed some of these skills during their studies, whereas many of the first-year students still had not had as much exposure to ICTs. A few examples of how students expressed their development of computer skills follow: "How to multitask on my laptop"; “...being able to read notes on my device”; "Being fast on my phone”; "Using shortcuts on my laptop"; and "Having to connect wi-fi to my laptop and downloading videos".

This also links to the theme that was indicated by the second-highest number of students in response to Question 2, namely developing typing skills. Student responses included the following: "My navigation with a keyboard.. I've learnt shortcuts"; "Typing as all the activities and assignment have to be typed"; "I used to type slow with my computer but write now I am way too good". The high number of students who indicated that their typing skills and speed have improved $(21.3 \%$ and $28.3 \%$ ) shows that many students are largely unfamiliar with using ICTs, particularly for learning. In our department, we adopted a policy during contact teaching to allow students to type or hand-write their assignments if they were unfamiliar with or lacked access to ICTs, but with online learning, even though some students still submitted handwritten assignments that were photographed and uploaded onto the LMS, the overwhelming majority typed their assignments or quizzes on their laptops or cell phones.

The high rate of ICT skills development indicates that many students still lack skills that are essential for online learning, and might require much more training on how to effectively use technologies before they embark on online learning, particularly at first-year level. Even though students at our university are required to do a course on ICTs, this does not seem to be sufficient in developing the skills that they need for online learning, and many students are left to develop these skills on their own. This also indicates that school-level training on using ICTs is insufficient in preparing students for online learning at university level, as almost half of firstyear students indicated that they developed computer skills through online learning. These data challenge the assumptions of students as "digital natives" (Prensky, 2001) simply due to their generational cohorts. The finding also calls into question whether students are actually developing skills equitably, and if some students might face increased difficulties in online learning because they could not access resources or were not comfortable enough with ICTs to learn these skills. This also raises the issue of which tools lecturers should use in online teaching-a plethora of impressive tools might be available for use, but does the variety of tools promote learning, or does it exclude many students due to them having to master all of these in addition to the content (cf. Smith's [2016] concept of technocratic engendering).

\subsubsection{Online learning skills}

In addition to the range of computer skills, a large number of students $(20.4 \%$ in English I and $18.9 \%$ in English II) also expressed becoming more comfortable with online learning, internet-based research and using the LMS for these courses. Students particularly highlighted how they were able to develop their skills of finding 
useful resources online to complete their assignments, as some students expressed: " $i$ am now more aware of where I get information for assignments or worksheets. $i$ also [f]ind it easier to find my [way] around websites/online platforms that I was not exposed to or comfortable with before"; "Being able to search more in an appropriate manner, being exposed to more new platforms I was not familiar with". Many students indicated that they improved their skills on how to engage in online forums, take online tests and navigate the LMS: "How to take tests online"; "...knowing how to find everything here in sakai [our LMS] has improved"; "Engaging in forums"; and "How to access sakai and forward emails when I don't understand".

This improvement of online learning skills demonstrated the initial challenges that students faced. Even though the LMS was already in use long before emergency remote teaching, the second-year students' responses showed that students were still unfamiliar with this essential tool and struggled with various aspects, indicating that students might have found ways around using this system, potentially due to experiencing it as obfuscating (cf. Smith, 2016). First-year students indicated that these skills improved at a marginally higher rate, but this difference was much smaller than for general computer or device skills, indicating that the LMS and online learning might be a relatively equal challenge for students at these two levels. This indicates that continuous training on using the LMS and on research skills might be required at multiple levels of study. Students might well complete coursework adequately, but might not access the full range of teaching and content available on the LMS due to not having sufficient experience and skills to do so. This might prevent students from reaching their full potential in online learning.

\subsubsection{Time management}

The final significant theme was time management. As highlighted in the responses to the first questions, many students expressed that time management was a significant struggle for them during lockdown, despite both authors significantly reducing the workload for the two courses. In the findings of those who mentioned improving their time management skills, it was significant that this accounted for only about half as many responses as for those who said that they struggled with time management in question 1 (9 vs 21 responses in English I, and 6 vs 10 responses for English II). Thus, many students who struggled with time management might not have found resources in the courses in order to improve their time management skills, or might have faced compounding struggles (like effectively engaging with online learning due to the level of skills required to do so) that made managing time a factor that could not be improved on.

However, the fact that $8.3 \%$ (English I) and 11.3\% (English II) of students in these courses indicated that they had developed better time management skills demonstrated how online learning required a greater degree of independence that made even a lower workload feel more challenging. Students responded in the following ways about developing time management skills: "The ability to work on multiple tasks in one time"; "to do things early as possible"; "self discipline"; "Writing and submitting in time.” 
One student also expressed that they appreciated having more time due to online learning in order to do their work: "I just have a lot more time to read and research more about any uncertainties with regards to my course work". However, it is worth noting that this student had an extremely positive experience of the course, strongly agreeing with all of the quantitative questions about the course despite identifying work space as a challenge, and thus might not have faced the same obstacles as many other students so could better manage their time. This indicates that under relatively favourable conditions, time management might actually become easier for some students with online learning, but these conditions do not exist for the majority of our students.

\subsubsection{Other skills improved}

The majority of other skills improvements indicated by students were under themes of collaboration and independence. Students expressed: "I have also learned how to work on my own and engage with other students via Microsoft teams and Zoom to work with the content and break it down together"; "being able to help others"; "working independently"; "I learnt how to study on my own". The factor of collaboration is generally seen to be an affordance of contact teaching. That students were able to find ways of collaborating in this unfamiliar online space, without being propelled to do so, is both surprising and heartening. It is an element that lecturers could work to consciously facilitate and encourage in online learning as it could combat the isolation, confusion and challenges with communication indicated by some students. Students in the English I course also identified developing their skills of reading and analysing texts (6 students, 5.5\%) and critical thinking (2 students, $1.8 \%)$, two elements that were important in the media studies course.

Finally, a large segment of students indicated not developing any online learning skills in the two courses. The reasons for this ranged from already having strong ICT skills and having learnt sufficient skills through the compulsory ICT course for firstyears. However, one student indicated that the structural problems mentioned in the previous section impacted on their lack of skills development: "Honestly, I did not acquire any skills because of an unproductive work space."

\section{Conclusion}

Smith (2016) warns against assuming that technology might be a "social justice panacea". Considering the student feedback analysed in this article, we concur with this. There are many good reasons for increasingly including online learning into a blended learning model at traditional contact universities, and this article does not aim to argue against that happening. We do, however, recommend caution when doing so, especially in contexts with as many vulnerable students as we have in South Africa. The Covid-19 pandemic has created unprecedented circumstances where most universities worldwide were forced into an accelerated online mode, and we acknowledge that under the circumstances, there were few manageable alternatives. The swift move towards online learning has, however, 
made glaringly obvious the thought and preparation that needs to go into planning future online and blended learning programmes for them to responsibly and ethically address the needs of all students.

Findings in this study have accentuated how the use of technology during the Covid-19 pandemic has widened the gap between students from various geographic and socio-economic backgrounds. For many of our students, technology has not acted as an equaliser. Instead, it has put tremendous pressure on our most vulnerable students, and has created a space which could easily render them faceless and voiceless, while inducing unprecedented anxiety. From a decolonial framework, it is vital to locate perspectives that idealise online learning within a "locus of enunciation" (Grosfoguel, 2007); in a country where economic and social inequalities are still mainly mapped racially and geographically, the view of learning technologies as "neutral" takes up the position of the middle-class, urban, mostly white and "Westernised" student who is part of a nuclear family structure and is a "digital native". In this way, technology can (advertently or inadvertently) be used to reinscribe colonial forms of oppression onto some students and further disempower them, and this, we believe, should be fervently guarded against.

It is important to note that our students have not been without agency, and have shown remarkable resilience under very challenging circumstances. Despite the isolation that Covid-19 has brought, and many of our students studying under extremely difficult circumstances, they have found ways to teach themselves computer and online learning skills. Many have found ways to effectively manage their time without traditional contact teaching structures to help them, and some have even found innovate ways of collaborating, while others learnt increased independence. Yet, the resilience on the part of our students cannot be an excuse for institutions of higher learning to shirk responsibility in preparing students for increased online learning. Students need resources beyond data and laptops. They need physical environments that are conducive to learning. Institutions have the responsibility to ensure that students are equipped with the skills necessary for engaging in online learning, and that they are given a voice in terms of how online content is structured and presented. It is unacceptable that many students only really learnt how to type or navigate our LSM in their second year of studies under very difficult circumstances, when these skills are often important to doing well even when the main mode of learning is through contact sessions. Thorough support of students in this regard, and considerations of their needs, are likely to help them to better manage workload challenges, and will likely give them more control in their online learning journeys. Lecturers, too, need to be made aware of the needs of a wide variety of students, and, importantly, capacity needs to be created for lecturers to be able to engage with the needs of their students. Overburdened lecturers, whose cultures, economic backgrounds and frameworks for knowledge might be very different from those of their students, will revert to familiar and traditional ways of teaching as a strategy to survive their own increasing workloads. This is entirely counterproductive in what should be a move towards critical digital pedagogy, and increasingly decolonised education.

The study aimed to clarify some of the challenges students face in emergency online teaching that took place due to the Covid-19 pandemic, and to speak about 
how students developed skills while learning online. In a higher education environment that is likely to move towards a more blended-learning model at a rapid pace after the Covid-19 pandemic, this research has provided insights into the realities of students within the South African context, that could aid lecturers and university managers to plan for equitable, empowering forms of blended learning for all students, including those most vulnerable. Findings can likely be extrapolated to not only universities in other developing countries, but also to those pockets of economically disadvantaged students living and studying in developed countries. Smith (2016) argues that "If technology is indeed central to conceptualizations of life and learning, its operation should be explored like other objects and ideas, which, in their own right, are often understood both in their production and consequence (...). When doing so, one can partake in a richer curriculum theorization of technology, one that accounts for the important dialectic between developer and user, subject and object". We hope that this advice will be heeded as higher education inevitably moves towards online teaching modes.

Data availability All data have been saved in a password-protected folder, and are available from the authors upon request.

Code availability Codes are available from the authors upon request.

\section{Declarations}

Ethics approval Ethics approval was obtained from the University of the Witwatersrand. The approval letter is added as an attachment.

Consent to participate All the participants were informed about the objectives of the study before taking the survey and the participation was voluntary and anonymous.

Consent for publication All authors agreed to submit this manuscript for publication.

Conflicts of interest/Competing interests The authors declare no conflict of interest.

\section{References}

Anthony, B., Kamaludin, A., Romli, A., Raffei, A. F. M., Abdullah, A., Ming, G. L., et al. (2019). Exploring the role of blended learning for teaching and learning effectiveness in institutions of higher learning: An empirical investigation. Education and Information Technologies, 24(6), 3433-3466. https://doi.org/10. 1007/s10639-019-09941-z

Babbie, E. (2013). The practice of social research $\left(13^{\text {th }} \mathrm{ed}\right.$.). Wadsworth Cengage.

Benaquisto, L. (2008). Codes and coding. In L. Given (Ed.). The SAGE encyclopedia of qualitative research methods (pp. 85-88). https://doi.org/10.4135/9781412963909

Businesstech. (2020). Government to take South Africa's universities online as student marks improve. Retrieved January 8, 2021, from https://businesstech.co.za/news/internet/452208/government-to-takesouth-africas-universities-online-as-student-marks-improve/.

Castro, M.D.B., Tumibay, G.M. (2021). A literature review: efficacy of online learning courses for higher education institution using meta-analysis. Education and Information Technologies, 26, 1367-1385. https://doi.org/10.1007/s10639-019-10027-z

Christie, M. J. (2004). Computer databases and aboriginal knowledge. Learning Communities: International Journal of Learning in Social Contexts, 1, 4-12. 
Cook, C. R., Coco, S., Zhang, Y., Fiat, A. E., Duong, M. T., Renshaw, T. L., et al. (2018). Cultivating positive teacher-student relationships: Preliminary evaluation of the establish-maintain-restore (EMR) method. School Psychology Review, 47(3), 226-243. https://doi.org/10.17105/spr-2017-0025.v47-3

Freire, P. (2005). Pedagogy of the oppressed (20th anniversary edition). Continuum.

Grosfoguel, R. (2007). The epistemic decolonial turn: Beyond political-economy paradigms. Cultural Studies, 21(2-3), 211-223. https://doi.org/10.1080/09502380601162514

Hinrichsen, J., \& Coombs, A. (2013). The five resources of critical digital literacy: A framework for curriculum integration. Research in Learning Technology, 21, 21334. https://doi.org/10.3402/rlt.v21.21334

Littlejohn, A., Beetham, H., \& McGill, L. (2012). Learning at the digital frontier: A review of digital literacies in theory and practice. Journal of Computer Assisted Learning, 28(6), 547-556. https://doi.org/10. 1111/j.1365-2729.2011.00474.x

Lynn, B., Prabhakaran, M., \& Sahai, A. (2004). Positive results and techniques for obfuscation. In C. Cachin \& J. L. Camenisch (Eds.), Advances in Cryptology - EUROCRYPT 2004. Lecture notes in computer Science. (Vol. 3027). Springer. https://doi.org/10.1007/978-3-540-24676-3_2

Margaryan, A., Littlejohn, A., \& Vojt, G. (2011). Are digital natives a myth or reality? University students' use of digital technologies. Computers \& Education, 56(2), 429-440. https://doi.org/10.1016/j.compe du.2010.09.004

Mendelson, A. L., \& Papacharissi, Z. (2010). Look at us: Collective narcissism in college student facebook photo galleries. The Networked Self: Identity, Community and Culture on Social Network Sites, 1974, 1-37. https://doi.org/10.4324/9780203876527-20

Mignolo, W. (2009). Epistemic disobedience, independent thought and de-colonial freedom. Theory, Culture \& Society, 26(7-8), 1-23. https://doi.org/10.1177/0263276409349275

Mignolo, W. D. (2007). Delinking: The rhetoric of modernity, the logic of coloniality and the grammar of decoloniality. Cultural Studies, 21(2-3), 449-514. https://doi.org/10.1080/09502380601162647

Nguyen, T. (2015). The effectiveness of online learning: Beyond no significant difference and future horizons. MERLOT Journal of Online Learning and Teaching, 11(2), 309-319.

Pikoli, Z. (2020). Academics reject claims that 2020 has been a success for universities. Daily Maverick. Retrieved January 9, 2021, from https://www.dailymaverick.co.za/article/2020-12-14-academics-rejectclaims-that-2020-has-been-a-success-for-universities/.

Prensky, M. (2001). Digital natives, digital immigrants part 2: Do they really think differently? On the Horizon, 9(5), 1-6. https://doi.org/10.1108/10748120110424843

Silva, J. M., \& The Students for Diversity Now. (2018). \#WEWANTSPACE: Developing student activism through a decolonial Pedagogy. American Journal of Community Psychology, 62(3-4), 374-384. https://doi.org/10.1002/ajcp.12284

Smith, B. (2016). Mobile applications and decolonization: Cautionary notes about the curriculum of code. Journal of Curriculum and Pedagogy, 13(2), 144-163. https://doi.org/10.1080/15505170.2016.11962 74

Valenzuela, A. (2019). The struggle to decolonize official knowledge in Texas' state curriculum: Side-stepping the colonial matrix of power. Equity \& Excellence in Education, 52(2-3), 197-215. https://doi.org/ 10.1080/10665684.2019.1649609

Van Gelderen, B., \& Guthadjaka, K. (2017). The Warramiri website: Applying an alternative Yolnu epistemology to digital development. Research and Practice in Technology Enhanced Learning, 12(1), 1-19. https://doi.org/10.1186/s41039-017-0052-X

Waddell, M., \& Clariza, E. (2018). Critical digital pedagogy and cultural sensitivity in the library classroom: Infographics and digital storytelling. College \& Research Libraries News, 79(5), 228. https://doi.org/10. 5860/crln.79.5.228

Zembylas, M. (2018). The entanglement of decolonial and posthuman perspectives: Tensions and implications for curriculum and pedagogy in higher education. Parallax, 24(3), 254-267. https://doi.org/10. 1080/13534645.2018.1496577

Publisher's note Springer Nature remains neutral with regard to jurisdictional claims in published maps and institutional affiliations. 